This item was submitted to Loughborough's Research Repository by the author.

Items in Figshare are protected by copyright, with all rights reserved, unless otherwise indicated.

\title{
Conflict among athletes and their coaches: What is the theory and research so far?
}

PLEASE CITE THE PUBLISHED VERSION

http://dx.doi.org/10.1080/1750984X.2016.1184698

\section{PUBLISHER}

(c) Taylor \& Francis

\section{VERSION}

AM (Accepted Manuscript)

\section{PUBLISHER STATEMENT}

This work is made available according to the conditions of the Creative Commons Attribution-NonCommercialNoDerivatives 4.0 International (CC BY-NC-ND 4.0) licence. Full details of this licence are available at: https://creativecommons.org/licenses/by-nc-nd/4.0/

\section{LICENCE}

CC BY-NC-ND 4.0

\section{REPOSITORY RECORD}

Wachsmuth, Svenja, Sophia Jowett, and Chris G. Harwood. 2019. "Conflict Among Athletes and Their Coaches: What Is the Theory and Research so Far?". figshare. https://hdl.handle.net/2134/24437. 
1 Running head: INTERPERSONAL CONFLICT

2

3

4

5 Although social and personal relationships are vital for productivity, health and wellbeing,

\section{Conflict among athletes and their coaches: What is the theory and research so far?}

Abstract

conflict is inevitable and is likely to cause upset and hurt feelings as well as anxiety and distrust (e.g., Jowett, 2003). Despite the potentially central role of interpersonal conflict in sport, researchers have yet to pay concerted attention to exploring the nature of conflict, its antecedents and consequences. Following a thorough literature search 80 research papers were identified, of which only a small number (6) studied interpersonal conflict directly, most captured dysfunctional interpersonal processes such as breakdown of communication. The current review aims to provide a critical summary of the existing literature around the psychological construct of interpersonal conflict, including its antecedents, management strategies and outcomes within the context of coach-athlete relationships as well as other relational contexts in sport. Based on the relevant literature, a framework of interpersonal conflict is proposed, which includes a specific focus on a key dyad within sport coaching namely the coach-athlete dyad. Future research directions and potential practical implications for sport psychology consultants, coach educators, coaches and athletes as well as other stakeholders are discussed. Keywords: conflict; framework; relationship; interdependency; communication; coach-athlete 
In high level sports where the stakes are high, outcomes unpredictable, and emotions

27 heightened, effective communication and appropriate behaviour may become challenging and

conflict can be provoked. Sport offers potential for conflict that can transpire as parental over- or under-involvement in their child/athlete's participation, administrators' excessive expectations of coaches, disagreements about team selection, power struggles between

teammates or athletes and their coaches, disagreements about training procedures (e.g., workload, goals, techniques) or even coaches’ interferences in athletes’ personal life (e.g., lifestyle, significant others).

Despite its prevalence, it is surprising how little we know about interpersonal conflict within sport. Sport psychology has paid considerable attention to understanding the interpersonal dynamics between coaches and athletes or members through theoretical models involving coach and athlete leadership (e.g., Chelladurai \& Saleh, 1980; Fransen, Vanbeselaere, De Cuyper, Vande Broek, \& Boen, 2014), coaches’ behaviours (Mageau \& Vallerand, 2003; Smoll \& Smith, 1989), coach-athlete relationship (Jowett \& Felton, 2014), communication/relationship strategies (Rhind \& Jowett, 2010), collective efficacy (Short, Sullivan, \& Feltz, 2005), and team cohesion (Carron, Widmeyer, \& Brawley, 1985). Nonetheless, there is dearth of research that explores interpersonal conflict among coaches, athletes and teammates. Subsequently, this scoping review aims to examine the extant literature with two central aims: a) to forward a definition of interpersonal conflict in sport and b) to propose a conceptual framework of interpersonal conflict in sport relationships primarily developed between coaches and athletes and team members. The intention of this article is to build momentum that would drive advancements in interpersonal conflict theory and research. 


\section{Methods}

Based on the novelty of the topic a scoping review was carried out investigating the

51 status quo of research on interpersonal conflict in sport relationships. This approach was

52 considered appropriate as it enabled the researchers to include studies focusing on

53 interpersonal conflict in-depth, but also scientific papers that broadly covered the area of

54 inquiry (Arksey, \& O'Malley, 2005). Moreover, qualitative, quantitative and theoretically

55 driven approaches could be integrated in the review process. Firstly, a systematic search of

56 scientific papers and book chapters was carried out using the following databases: Web of

57 Science, ScienceDirect, SportDiscuss, PsychInfo, PsycArticles, OvidSP, PubMed, ProQuest,

58 SPONET, and Scopus; results generated a total of 6201 hits. All references were examined

59 and key references extracted. These were used to identify further relevant articles. To be

60 considered for inclusion, scientific papers had to demonstrate a number of general criteria: 1)

61 relevance to the research inquiry, 2) publication in peer reviewed journals, conference

62 proceedings or book chapters, and 3) written in English or German language according to the

63 native languages of the main researchers. A first examination led to the exclusion of 6020

64 references, including double positive and inaccessible sources. The remaining 180 articles

65 underwent a more thorough review where sound methodological standards, clear reasoning

66 for the conducted research, relevance to the current investigation and coverage of diverse

67 participant perspectives (athletes, coaches, external agents) were considered. Moreover, four

68 papers and one conference presentation were added after the original review process due to

69 later publication dates. A final sample of 80 articles was included in the review, these are

70 marked with an asterisk $(*)$ in the reference list. Despite the rather large number, only six of

71 these articles directly focused on conflict experiences ( $1 \mathrm{x}$ interpersonal conflict, $5 \mathrm{x}$ intra-

72 team conflicts). An additional four examined intra-team communication, and another three

73 covered conflict management and team building. Within the remaining 67 papers conflict was 
74 mentioned peripherally. In the final stage, a theoretically driven thematic analysis (Dixon-

75 Woods, Agarwal, Jones, Young, \& Sutton, 2005) of the literature was conducted.

76 Subsequently, four areas of interest were identified: 1) a definition of interpersonal conflict in

77 sport relationships (e.g., coach-athlete, peer relationships), 2) determinants of interpersonal

78 conflict (e.g., personality, relationship quality), 3) prevention and management (e.g.,

79 communication, problem-solving), and 4) conflict consequences (e.g., well-being, 80 performance).

81

82

83

84

85

86

87

88

89

90

91

92

93

94

95

96

97

98

\section{Results}

Based on the thematic analysis of the identified papers, a definition of interpersonal conflict and an exploratory conceptual framework for understanding interpersonal conflict in sport relationships are proposed (Figure 1). The identified literature focuses heavily on the coach-athlete relationship, but also draws on research findings on peer conflict. Therefore, the term 'sport relationships' refers directly to those core relationships between coaches and athletes as well as team members throughout this paper.

The framework as displayed in Figure 1 integrates main areas of interpersonal conflict and can be split in three different sections: 1) determinants, such as intrapersonal, interpersonal and external factors; 2) cognitive, emotional and behavioural processes associated with conflict (including initial reactions and management behaviours); and 3) intrapersonal, interpersonal and performance consequences. Hence, it accounts not only for factors related to the individual conflict parties, but also interpersonal relationship characteristics, external circumstances and sport performance which may influence interpersonal interactions.

\section{Developing a Definition of Interpersonal Conflict within Sport Relationships}

Despite the extensive research concerning conflict within both organisational and social psychology, the concept of conflict remains unclear, complicated, and controversial. Barki 
and Hartwick (2004), scholars in organisational/management psychology, explained that not only the lack of a clear conceptualisation of the construct of conflict but also the lack of its operationalization has made it extremely challenging to compare results of different studies and has prevented the development of knowledge within the conflict domain. For example,

103 interpersonal conflict has been described in terms of where it occurs (e.g., organizational 104 conflict; Rahim, 2002), its various dimensions (e.g., moral conflict; Duquin \& Schroeder105 Braun, 1996), or orientations (e.g., task, relationship; Barki \& Hartwick, 2004). Amason (1996) distinguished conflict by its outcomes (functional vs. dysfunctional) and its underlying 107 processes (cognitive vs. affective). Further, Barki and Hartwick (2004) focused on conflict 108 parties when differentiating between intrapersonal, interpersonal, intra-group and intergroup 109 conflict. Finally, conflict as a psychological concept has been confounded with such terms as 110 abuse, mistreatment, and aggression (e.g., Duquin \& Schroeder-Braun, 1996). Thus, conflict

111 requires a definition that describes what this concept represents and what it does not.

112 Accordingly, it needs to be acknowledged that conflict is more than a mere (cognitive)

113 disagreement between people, but it also involves strong emotional reactions (e.g.,

114 frustration) and interfering behaviours (e.g., confrontation, social isolation) (e.g., Paradis, 115 Carron, \& Martin, 2014a).

Drawing from the sports literature. Within the sport literature, only a few empirical

117 studies have directly examined the concept of conflict. In one of them, Mellalieu et al. (2013)

118 investigated interpersonal conflict at the highest level of competition including European

119 Championships, World Cups and Olympic Games. Findings revealed that conflict was 120 experienced by nearly 75\% of participants $(N=90)$ who occupied roles as coaches, athletes,

121 managers and external agents. They described conflict as short-lived and occurring only a

122 few times during major events, however, long-term conflict was also reported among

123 participants of all groups. Mellalieu et al.'s (2013) study offered a first insight into conflict in 
124 sport and while they highlighted its negative content and outcomes, they also explained that

125

126

127 Knight, and Zukiwski (2012) and Paradis et al. (2014a, 2014b) who focused on athletes'

128 perceptions of intra-team conflict. Drawing on the work of Barki and Hartwick (2004),

129 Paradis et al. (2014a) defined conflict based on the co-occurrence of its three dimensions:

130 cognitive, affective and behavioural responses. The interviewed athletes described cognitive

131 not all participants experienced conflict during competitions.

A more in-depth description of the nature and content of conflict was offered by Holt, conflict as a disagreement about goals, strategies, opinions or a "clash of personalities" and considered it to be the "heart of conflict" (Paradis et al., 2014a, p. 12). The affective dimension was seen as a tense atmosphere with negative emotions, that fosters the potential for conflict escalation. Lastly, behavioural expressions of conflict included verbal or physical responses, like blaming, fighting or negative body language. Furthermore, task and relational types of conflict cut across the three dimensions of conflict mentioned earlier. Here, relationship conflict was associated with negative relations outside the sport, long-term isolation of athletes, severe interference of one's behaviour and a spread of negative emotions within the team. Overall, the participants of this study emphasized the negative nature of conflict. Correspondingly, Partridge and Knapp (2015) described that intra-team conflict was manifested in direct or indirect victimization (e.g., aggressive behaviours, isolation, rumours, dirty looks) of individuals and was based on experienced disagreements or disputes. They suggested that conflict would negatively influence individual well-being, team cohesion and therefore also performance. This assumption is in line with Leo, Gonzalez-Ponce, SanchezMiguel, Ivarsson, and Garcia-Calvo's (2015) findings who viewed conflict as a negative interference of one individual's interests by another party and proposed that both, relationship and task conflict, led to a decrease in collective efficacy within female football teams. Collectively, these findings are consistent with a study conducted by Holt et al. (2012). They 
149 explained that social (interpersonal or relationship) conflict was a dysfunctional process

150 which was potentially harder to solve. On the other hand, they pointed out that task conflict,

151 which addressed practice, competition or playing time, could be functional at times as it

152 reminded athletes that developing skills and improving performance were central to their

153 programme and subsequently development.

154 Defining interpersonal conflict. Considering the coverage of interpersonal conflict

155 within sport psychology (albeit limited) as well as diversity and complexity of conflict within

156 the wider psychology literature (e.g., Barki \& Hartwick, 2004; Paletz, Miron-Spektor, \& Lin,

157 2014), we decided to integrate the various components of conflict discussed earlier and draw

158 a definition of interpersonal conflict in sport relationships. Proposing a definition of

159 interpersonal conflict is important because it provides the boundary conditions of the concept

160 under scrutiny. In this paper, we define interpersonal conflict as a situation in which

161 relationship partners perceive a disagreement about, for example, values, needs, opinions or

162 objectives that is manifested through negative cognitive, affective and behavioural reactions.

163 Moreover, interpersonal conflict is influenced by the social and cultural context within which

164 it occurs, including individuals' characteristics, personality, age and gender. It is noteworthy

165 that the definition does not imply a static conceptualization of conflict; conflict is described

166 as a situation and this reflects a dynamic process that may last over a prolonged period of

167 time (episode) and can re-occur several times (frequency). The nature of interpersonal

168 conflict is presented as the core of the proposed conceptual framework.

169 An essential requirement of conflict is a perceived disagreement between individuals

170 which is reflected in cognitive processes based on a negative interdependence of conflict

171 parties (Deutsch, 1969), for instance, when one’s goal achievement is potentially impeded by

172 the other's behaviour. This cognitive dimension of conflict involves, but is not limited to

173 disagreements about personal objectives, mismatching values, opposing needs and interests 
174 or limited resources and is expressed by spontaneous conflict behaviours. Moreover,

175 individuals are likely to experience initial negative emotions, such as anger and aggression

176 (hard emotions; associated with power and selfishness) or disappointment and sadness (soft

177 emotions; pro-social, associated with vulnerability; Sanford, 2007). Finally, individuals may

178 perceive the intensity of conflict differently (more or less severe), depending on their

179 personality, culturally determined role expectations or collectivistic-/ individualistic-

180 orientation (Paletz et al., 2014). However, it remains to be explored how individual

181 perceptions, characteristics, and social interaction shape conflict experiences within sport.

182 Determinants of Conflict: Intrapersonal, Interpersonal and External Factors

As presented in the first part of Figure 1, conflict may be caused and further

184 influenced by both intrapersonal factors, such as personality, worldviews, self-esteem,

185 motivation, competence, as well as skills, experiences and qualifications (e.g., Greenleaf,

186 Gould, \& Dieffenbach, 2001; Jowett, Lafreniere, \&Vallerand, 2012), and by interpersonal

187 factors, such as incompatibility, poor communication and relationship quality, or ineffective

188 motivational climate and leadership (e.g., D’Arripe-Longueville, Fournier, \& Dubois, 1998;

189 Jowett \& Cockerill, 2003). These determinants can function independently in a co-existing

190 manner, but also interact with each other. For example, a less desirable personality

191 characteristic such as neuroticism (i.e., emotionally unstable, continuously worried) and an

192 anxious attachment style (i.e., excessively dependent, possessive) may contribute to the

193 experience of conflict or disagreement. These personality characteristics may also be coupled

194 with low levels of trust, both uni- and multi-directional, exacerbating the conflict

195 experienced. Alongside personal and interpersonal determinants, also external factors,

196 including situational circumstances, social and social-cultural differences (e.g., language,

197 customs) can cause conflict.

198 Intrapersonal factors. 
Stable intrapersonal factors. Interpersonal factors can be grouped into stable (traits) and situational (states) attributes. For example, one of these stable intrapersonal factors which are related to perceptions of interpersonal conflict is gender; it has been found that male athletes engage in more conflict behaviour and conflict communication with their peers than females (Sullivan, 2004; Weiss \& Smith, 2002). Another example of stable intrapersonal factors included personality traits of dyadic partners. Research indicated that personality may be linked to interpersonal conflict in sport relationships (Holt et al., 2012; Magnusen, 2010). Based on the Big 5 personality model (Costa \& McCrea, 1992; Digman, 1990) Jackson, Dimmock, Gucciardi, and Grove (2010, 2011) conducted two studies investigating the relationship quality of athlete-athlete and coach-athlete dyads, respectively. Results indicated that dissimilarities between partners regarding extraversion and openness were associated with more unstable, dysfunctional and incompatible relationships all of which were likely to facilitate conflict. Yang, Jowett, and Chan (in press) also found that neuroticism was associated with less than optimal coach-athlete relationships.

214 relationship quality and the experience of conflict (Davis \& Jowett, 2014; Felton \& Jowett, 215 2013c). Thus, secure attached athletes reported only minor conflicts with their coaches as they are more likely to have developed better social and interpersonal skills (e.g., effective 217 communication) (Davis \& Jowett, 2014). Similarly, avoidant attached athletes perceived little 218 conflict with their coaches, which might be caused by a tendency to avoid close interactions 219 or close bonds with others. It may be interesting to see whether similar patterns are found for 220 other sport relationships, such as athlete-athlete dyads or within teams.

Situational intrapersonal factors. When considering interactions between coaches

222 and athletes as well as between athlete-peers less stable intrapersonal factors (states) also 223 need to be taken into account. One of these is passion which is defined within sport as a 
224 "strong inclination toward an activity that people like, that they find important, and in which

225 they invest time or energy” (Vallerand \& Miquelon, 2007, p. 250). Passion is generally

226 categorized into obsessive (internal forces, lack of control) and harmonious (personal

227 endorsement, personal choice) passion, which have been found to relate differently to the

228 experience of interpersonal conflict in sport. Accordingly, Jowett, Lafreniere, and Vallerand

229 (2012) stated that athletes' and coaches' obsessive passion was positively associated with

230 perceived interpersonal conflict in coach-athletes dyads, and further, a coach's obsessive

231 passion was predictive of lower personal satisfaction and higher perceptions of athletes'

232 conflict. However, this finding was not replicated within sport teams. Accordingly, the

233 findings by Paradis et al. (2014b) did not show a significant association between obsessive

234 passion and team conflict, while harmonious passion was inversely related to team conflict.

235 The role of passion differs regarding the experience of conflict within the relationship quality

236 developed among teammates and coaches-athlete dyads. These differences may be due to

237 diverse expectations and relationship characteristics. However, research on athlete-athlete

238 relationships is scarce and therefore no certain conclusions can be drawn.

239 Recently, efficacy beliefs have received empirical research within the context of

240 sport. Jackson and his colleagues introduced the notion of tripartite efficacy; a set of

241 psychological efficacy beliefs that include self-efficacy, others-efficacy and relation-inferred

242 self-efficacy (RISE) that have been found to determine relationship quality in sport dyads

243 (Jackson, Grove, \& Beauchamp, 2010; Jackson, Gucciardi, \& Dimmock, 2011; Jackson,

244 Knapp, \& Beauchamp, 2008). Specifically, a partner's low perception of an athlete's/coach's

245 self-efficacy was stated as a factor for relationship termination in both, athlete-athlete and

246 coach-athlete dyads, whereas a partner's higher ratings were connected to a greater

247 relationship satisfaction when actor-partner interdependence models were conducted (Jackson

248 et al., 2011). Investigating tripartite efficacy profiles via cluster analyses of coach-athlete 
249 dyads, they further observed a link between unfulfilled tripartite profiles of athletes and

250 higher perceived interpersonal conflict with their coaches; in opposition, fulfilled profiles

251 related to higher relationship commitment and satisfaction. Overall, perceived confidence and

252 competence of a dyad member seemed to play a major role in maintaining an effective

253 relationship. This conclusion has been supported by several studies investigating athletes'

254 perceptions on good and bad coaching behaviours (e.g., Becker, 2009; Gearity, 2012; Gearity

255 \& Murray, 2011). Specifically, conflict seemed to occur due to perceived incompetence

256 (Greenleaf et al., 2001; Hanton, Fletcher, \& Coughlan, 2005; Jowett \& Cockerill, 2003),

257 disagreements upon one's training schedule and workload (Greenleaf et al., 2001; Jowett,

258 2003) or handling of injuries (Greenleaf et al., 2001; Shrier, Safai, \& Charland, 2014).

259 Considering the task-orientated purpose of a coach-athlete relationship where performance

260 improvement is central (Jowett \& Shanmugam, in press), these findings seem very plausible

261 as athletes' performance success and wellbeing are to a degree dependent on their interactions

262 with their coaches and the coaches' instructions, knowledge and experience. Subsequently,

263 when investigating interpersonal conflict in sport, research that aims to explore specific

264 intrapersonal factors, such as personality, competence or efficacy beliefs, is warranted.

265 Interpersonal factors. Whereas intrapersonal factors are likely to impact the quality

266 of the interaction between people, the level of interdependence, relationship quality,

267 communication, group unity, and co-operation may also affect the experience of conflicts

268 (Figure 1).

269 Interpersonal relationships. Within sport, the coach-athlete relationship has attracted

270 a concerted research effort. Jowett's 3+1Cs model (Jowett \& Shanmugam, in press) provided

271 the impetus needed when Wylleman (2000) described the concept of the coach-athlete

272 relationship as an "uncharted territory". The model is concerned with coaches' and athletes'

273 affective closeness (e.g., mutual trust, respect), cognitive commitment (e.g., thoughts of 
274 maintaining a close relationship over time) and behavioural complementarity (e.g., co-

275 operative acts of interactions), as well as co-orientation (e.g., perceptual agreement). Within

276 this literature, it has been postulated that low levels of closeness, complementarity,

277 commitment and co-orientation can have a negative impact on the quality of the coach-athlete

278 relationship and potentially lead to a regressive spiral of recurrent interpersonal conflict that

279 could even cause relationship termination (Jowett \& Cockerill, 2003). Jowett (2003)

280 described the characteristics by which an athlete experienced conflict relative to her coach as

281 follows: (a) low (intensity) and negative (quality) closeness and reflecting in feeling

282 unattached, distant, distressed, frustrated and even rejected; (b) non-complementary

283 transactions that were manifested in power struggles and opposed behaviours; (c) lack of

284 commitment or willingness to maintain a close bond with each other over the foreseeable

285 time leading to the termination of the relationship; and finally (d) dis-orientation or lack of

286 agreement was said to be leading to disputes, contested views, and disagreements. In

287 conclusion, interpersonal conflict may be associated with either one or all dimensions of

288 relationship quality (closeness, complementarily, commitment, co-orientation) as they are

289 capable of dis-stabilising the symmetry and evenness (stability and harmony) that

290 characterise effective and successful relationships (Jowett, 2005). Empirical research has

291 substantiated these initial assumptions by linking closeness, commitment, and

292 complementarity with interpersonal conflict (Jowett, 2009). Interestingly though, it has also

293 been noted that the more interdependent relationships are, the more likely conflict will occur

294 (Stirling \& Kerr, 2009). Therefore, relationship characteristics are not only determinants to

295 relationship quality, but they are rather also defined by interpersonal processes,

296 environmental factors, and intrapersonal factors and hence, cannot be discussed in isolation.

297 Communication. Communication, for example, is an essential process at all stages of

298 relationship development and maintenance as it provides the members with information about 
299 one another and fosters closeness, commitment, and complementarity; thus the simple

300 process of getting to know the other person, her or his needs and expectations are central to

301 effective and successful interactions (LaVoi, 2007). Communication also plays a major role

302 in developing and maintaining an effective coach-athlete relationship (Rhind \& Jowett,

303 2010). For instance, Trzaskoma-Bicsérdy, Bognár, Révész, and Géczi (2007) explained that

304 while all coach-athlete dyads may encounter difficulties at some point in their collaboration 305 and athletes might feel unsupported, misunderstood or isolated, these issues can be solved by 306 openly discussing their differences. Hence, the role of communication is instrumental in 307 preventing, processing and resolving conflict (Rhind \& Jowett, 2010).

Failing to communicate effectively, in contrast, has been suggested as one of the main 309 characteristics of poor coaching (Gearity \& Murray, 2011; Scanlan, Stein, \& Ravizza, 1991). 310 Interestingly, that does not only concern the coach-athlete relationship, but also unsatisfying communication patterns within coaching teams and sport organisations which are directly or indirectly affecting individuals perceptions and coach-athlete interactions (e.g., D’Arripe313 Longueville, et al., 1998; Kristiansen, Tomten, Hanstad, \& Roberts, 2012). reported a breakdown of interaction and communication as the most common determinant to conflict as it was mentioned by over $50 \%$ of the study's participants. Similarly, several

317 studies have cited a lack of communication as underlying factor of perceived struggles or 318 conflicts between coach-athlete/ athlete-athlete dyads or within coaching teams and sport 319 organisations. (e.g., Culver \& Trudel, 2000; Hanton et al., 2005; Jowett \& Frost, 2007;

320 Kerwin, Doherty, \& Harman, 2011). However, these investigations have so far failed to 321 provide any specific information on in-/effective communication patterns. 
324 (1998) and Purdy, Potrac, and Jones (2008) described how coaches used a communication 325 style which was characterized as loud, distant, and angry and included negative strategies 326 such as bossing athletes around and blaming. Additionally, Purdy et al. (2008) emphasized 327 that conflict escalation may be promoted by coaches who are ignorant, deliberately withhold 328 information and restrict communication. Lastly, hostile and inadequate reactions in critical 329 situations during practice or after unsuccessful competitions may also be the mere expression 330 of conflict (e.g., Purdy et al., 2008; Sagar \& Jowett, 2012). Sullivan and Feltz (2003) developed a questionnaire to assess typical communication 332 patterns in sport teams; it contained four dimensions, two of which measured negative 333 conflict and positive conflict. Negative conflict captures the expression of agitation or anger 334 as well as its emotional, personal and confrontational nature, whereas positive conflict captures constructive and integrative ways of dealing with disruption. A number of studies have used this assessment tool in studies that examined group dynamic variables such as role 337 ambiguity, cohesion and leadership (Cunningham \& Eys, 2007; Smith, Arthur, Hardy, 338 Callow, \& Williams, 2013).

Team processes. Apart from relationship and communication that may be responsible

340 for the onset of conflict, team processes form another set of dimensions that may be

341 significant sources of interpersonal conflict. Research has shown that a less task- and more

342 ego-involving climate is correlated with negative perceptions of peer relations, less perceived 343 acceptance within a team and increased perceived conflict between team members (e.g.,

344 Ommundsen, Roberts, Lemyre, \& Miller, 2005; Smith, Balaguer, \& Duda, 2006). Moreover, 345 while strong relations between coaches and athletes have been found to associate positively 346 with team cohesion and collective efficacy (e.g., Hampson \& Jowett, 2014; Jowett \& 347 Chaundy, 2004), poor relations between coaches and athletes have been found to facilitate 348 intra-team rivalry and power struggles (e.g., D’Arripe-Longueville et al., 1998; Holt et al., 
349 2012; Kristiansen et al., 2012). Those may lead to jealousy or strong attitudes among team 350 members resulting in even more conflict (Partridge \& Knapp, 2015). Furthermore, Hardy,

351 Eys, and Carron (2005) found that high task-cohesion may lead to conflict or even a

352 breakdown of friendships due to a performance-oriented, competitive team climate. In

353 another study, Paradis, Carron, and Martin (2014b) showed that both task and social conflict

354 were negatively related to all dimensions of team cohesion. However, due to the correlational 355 research design no conclusions about causal effects were made. Overall, it would seem that more interpersonal conflict is caused by loose interpersonal social and task connections and equally, interpersonal conflict may also be the reason for lower cohesion due to, for example,

358 disagreements and discrepant goals. Role ambiguity between team members has also been

359 found to cause interpersonal conflict, especially if athletes and coaches do not appreciate, 360 understand and carry out their role responsibilities (Benson, Eys, Surya, Dawson, \& 361 Schneider, 2013). It is important to note here that often the athlete leader is seen to be responsible for solving conflicts among team members or to mediate between coaching staff and athletes (Fransen et al., 2014).

Leadership and power. One condition for the above point to work is that it requires the coach and athlete leader to relate and cooperate effectively. Dysfunctional relationships between coaches and their captains, on the other hand, have been found to lead to miscommunication and lacking information flow between the coaching staff and team, causing further trouble for team members (Dupuis, Bloom, \& Loughead, 2006). 
374 turn is associated with conflict and distress (Potrac \& Jones, 2009; Scanlan et al., 1991).

375 Moreover, an indecisive coach may cause conflict with athletes, especially when facing

376 critical situations under high pressure (Hanton et al., 2005). Furthermore, a lack of supportive

377 behaviours has been mentioned to foster conflict within coach-athlete dyads (e.g., Hanton et

378 al., 2005; Jowett, 2003; Jowett \& Cockerill, 2003). Another source of conflict is represented

379 by power abuse of coaches or power struggles between coaches and athletes. Power abuse

380 might occur in very different forms, such as punishment after mistakes or defeat (Sager \&

381 Jowett, 2012), when undermining athletes’ experiences, opinions and needs (Jowett, 2003),

382 controlling the private life of athletes, harassment (Tomlinson \& Yorganci, 1997), as well as

383 emotional or physical abuse (Stirling \& Kerr, 2009). These negative coaching behaviours

384 may furthermore lead directly to conflict (e.g., Stirling \& Kerr, 2008; Tamminen et al., 2013)

385 or to negative responses by the athletes (e.g., Stirling \& Kerr, 2008, 2009) who are facing

386 these conflicting situations (Duquin \& Schroeder-Braun, 1996).

External factors. Besides antecedents that reside within or between relationship

388 members, there are also antecedents that are external to them and can influence the onset of

389 interpersonal conflict. These variables may be located in the wider situational and

390 environmental circumstances surrounding the relationship members; they may be situational,

391 (e.g., practice location) or permanent (e.g., culture or ethnical background) (see Figure 1).

392 There has been evidence to indicate that discrimination, inequality and stereotypical thinking 393 exists in semi-professional soccer players, among fans, opponents and teammates, as well as 394 coaches (e.g., Jowett \& Frost, 2007; Khomutova, 2015). Such discriminatory behaviours 395 (e.g., prejudice, unfairness, favouritism) are less tolerable and may lead to conflict if players 396 do not perceive them somewhat with a sense of humour or ignorance to prevent escalated 397 trouble (Jones, 2002). Also gender may lead to very similar experiences within sports; 398 female sport participants are often associated with stereotypes of homophobia, lack of 
acceptance or lack of perceived competence (e.g., LaVoi \& Dutove, 2012; Mazerolle,

400 Bruening, \& Casa, 2008; Shaw \& Allen, 2009). Correspondingly, female coaches have

401 described their work as being inhibited by higher positioned male coaches, not accepted by

402 male athletes and disesteemed due to stereotypical and sexual assumptions. Similarly, female

403 athletes have been found to be treated in inferior manners to male athletes and therefore

404 experience conflict during mixed practices or competitions (Tomlinson \& Yorganci, 1997).

405 Moreover, a number of studies recently have investigated organisational stressors

406 within sports. These studies revealed that such stressors are linked to interpersonal conflict

407 with team management/ headquarters of the organization, support networks, administrators,

408 or judges (Fletcher \& Hanton, 2003; Fletcher, Hanton, Mellalieu, \& Neil, 2012; Hanton,

409 Fletcher, \& Coughlan, 2005). In line, old-fashioned systems within clubs or national

410 associations might restrict the flexibility to build up athlete-centred, flexible practice

411 environments and effective coach-athlete relationships (D'Arripe-Longueville et al., 2001;

412 Kristiansen et al., 2012). Additionally, parents have been reported to engage in direct conflict

413 with coaches, with other athletes or with their own athlete-children - preventing them from

414 forming a close relationship with coaches (Jowett \& Timson-Katchis, 2005; Lauer, Gould,

415 Roman, \& Pierce, 2010; Scanlan et al., 1991; Weiss \& Fretwell, 2005) or stirring intra-team

416 conflict (Partridge \& Knapp, 2015).

417 Lastly, situational circumstances may refer to disagreements about issues that directly

418 concern both the coach and the athlete, such as training and competition schedules,

419 expectations, values or interpersonal differences especially as these can be developed

420 following a significant change of events within or outside the relationship (e.g., Gould,

421 Greenleaf, Guinen, \& Chung, 2002; Greenleaf et al., 2001; Jowett, 2003; Kristiansen et al.,

422 2012). Winning an Olympic medal, for example, can be followed by a chain of negative

423 changes, such as disagreements about goals, pursuing conflicting personal ambitions, media 
424 distractions or reports or being influenced by externals, such as agents (Jowett, 2003).

425 Speaking of major competitions, it might be the case that personal or local/club coaches

426 cannot support their athletes during competitions but are instead replaced by the national or

427 another coach. In this case conflict can be caused due to non-established relationships,

428 contrasting instructions from coaching staff or a lack of communication within the coaching

429 team (e.g., Jowett, 2008; Kristiansen et al., 2012). Additionally, team selection processes may

430 lead to conflicts between athletes and the coaching staff or even the sport organisation

431 (Fletcher \& Hanton, 2003; Gould et al., 2002; Kerwin, Doherty, \& Harman, 2011) and thus

432 how team selection is being communicated may be paramount to relationship development.

433 In sum, the extant literature seems to indicate that interpersonal conflict can be caused

434 by intrapersonal, interpersonal and external factors, such as expectations, misunderstandings,

435 or even bad intentions. This review highlights that understanding the determinants of

436 interpersonal conflict in sport would help identify and facilitate conflict management and

437 resolution strategies based on the causes of it. While more focused research efforts are

438 required to examine the antecedents of interpersonal conflict in sport more directly, the next

439 section discusses strategies that have been found to be employed in an attempt to manage and 440 resolve conflict.

\section{Conflict Prevention, Management and Resolution}

442 Considering that individuals usually engage in relationships for a purpose it is likely

443 that they will try to protect it from harm or even termination (Carron \& Brawley, 2012).

444 Conflict, however, represents a risk to any relationship if not dealt with constructively.

445 Therefore, relationship partners may want to prevent situations in which conflict can erupt,

446 for example by using relationship maintenance strategies, such as setting common goals,

447 mutual assurance, open communication, or making use of constructive problem-solving

448 strategies after disagreements (Rhind \& Jowett, 2010, 2011). Accordingly, the process of 
449 stopping the onset of conflict is called conflict prevention; it can include general relationship

450 maintenance strategies as well as behaviours focusing specifically on potential

451 disagreements. Slightly more controversial is the categorization of conflict behaviours that

452 are shown after the onset of conflict. Thus, conflict styles describe individuals' preferences to

453 engage in certain conflict management and/or resolution behaviours (e.g., collaborative,

454 competitive or avoidant behaviours; Volkema \& Bergmann, 1995). Conflict management,

455 furthermore, refers to the use of effective behavioural strategies to reduce dysfunctional conflict and to facilitate constructive conflict (e.g., information sharing, goal setting, role clarification). In contrast to conflict resolution strategies (e.g., negotiation, bargaining,

458 mediation), conflict management does not necessarily aim to diminish or terminate conflict

459 (Rahim, 2002). Generally, it can be expected that relationship partners will engage in conflict management and/or resolution strategies, after conflict prevention has failed. Within a

461 feedback-loop the nature of a conflict, described by content (cognitions, emotions,

462 behaviours), duration and intensity, will influence and be influenced by these conflict 463 behaviours (see Figure 1).

464 Conflict prevention. As stated before, conflict prevention is not only dependent on 465 intra- and interpersonal characteristics, but also on the potentially identified disagreement. 466 Hence, conflict parties may engage in self-reflection processes and gather further information 467 about potential topics of disagreement, develop sound communication skills, avoid 468 conflicting situations or accept inequitable attitudes (D'Arripe-Longuevill et al., 1998; 469 Gearity \& Murray, 2011; Langan, Blake, \& Lonsdale, 2013; Stirling, 2013). However, first 470 and foremost, all involved parties need to be willing to engage in constructive behaviours in 471 order to maintain the relationship. With the COMPASS Model (Rhind \& Jowett, 2010, 2011) 472 a theoretical framework integrating behaviours that aim to maintain and enhance the coach473 athlete relationships was developed. Listed are reactive and proactive strategies concerning 
474 conflict management, openness, motivation, prevention, assurance, support and social

475 networks (Rhind \& Jowett, 2011, 2012). Interestingly, the majority of strategies target the

476 prevention of conflict, for example by being honest, giving constructive feedback and setting

477 common goals (Jowett \& Shanmugam, in press). Other strategies include coaches employing

478 an open-door policy, showing interest in the athlete as a person and establishing rapport (e.g.,

479 Becker, 2009; Bennie \& O'Connor, 2012). Besides imparting maintenance strategies, Jowett

480 and Carpenter (2004) further indicated the establishment of rules within coach-athlete dyads

481 in order to prevent interpersonal conflict. These rules may cover certain role expectations of

482 coaches and athletes. Within the framework of complementarity in the coach-athlete

483 relationship, Yang and Jowett (2013) explained that athletes and coaches assume distinct

484 roles, where athletes usually have submissive roles reflected in the expectation to execute

485 instructions and consider advice whereas coaches usually assume dominant roles reflected in

486 the expectation to be in charge and provide instruction and feedback. Yang and Jowett (2013)

487 made it clear that these behaviours represent role expectations which aim to provide structure

488 and organisation (Jowett \& Carpenter, 2004); they are not synonymous to controlling

489 behaviours as understood within the self-determination theory (Ryan \& Deci, 2000).

490 Consequently, while great coaches should aim to fulfil basic psychological needs they also

491 should recognize and meet athletes’ needs for structure and guidance (cf. Ryan \& Deci, 2000;

492 Becker, 2009). Accordingly, pursuing a balance between facilitating an athlete’s

493 independence and connection, without making him or her feel left alone and helpless or

494 making him or her controlled by the coach, within a well-defined coaching structure,

495 provides one of the many challenges of great coaching.

The establishment of high-quality relationships between a coach and each individual

497 athlete in the team and the creation of an atmosphere of trust, respect and honesty is also

498 likely to influence team dynamics positively and will facilitate bonding processes among 
499 team members (e.g., role modelling, communication and conflict culture); therefore, building

500 a strong, common network in which individuals can rely on each other should be a priority

501 (Rhind \& Jowett, 2010). Efforts here should be directed at establishing trust and respect,

502 facilitate open, positive communication, setting a common ground for team members and

503 fostering team cohesion (Copeland \& Wida, 1996; Evans, Slater, Turner, \& Barker, 2013;

504 Hardy \& Grace, 1997; Smith, 2001). Close relationships among team members may

505 encourage individual players to emphasize a more task involving team climate, including

506 mutual support and encouragement also in difficult situations (Smith \& Smoll, 1997) and

507 therefore also enable team members to discuss problems openly as well as engaging in co-

508 operative, effective conflict resolving strategies (Holt et al., 2012). Moreover, high quality

509 relationships are also a core element of team resilience; communication, for example, forms

510 an essential ingredient in building and maintaining a group structure which is likely to ensure

511 stability and organisation during times of crisis, such as conflict (Morgan, Fletcher, \& Sarkar,

512 2013). Accordingly, a well-established group identity may prevent conflict due to lower ego-

513 involvement and salient collectivistic thought processes. It might also enable group members

514 to focus on task issues instead of targeting personal relationships directly. Taken together,

515 based on the reviewed literature we recommend to create high-quality relationships between

516 coaches and athletes, just as between peers by relying on stable communication, mutual care,

517 trust, respect, reliability and common expectations in order to prevent conflict.

518 Conflict management and conflict resolution. Despite coaches' and athletes’ best

519 efforts to prevent conflict there may be times where conflict occurs and its management

520 becomes paramount. In fact, it has been acknowledged that conflict is inevitable in

521 relationships and the more interdependent the relationships the higher is the likelihood of

522 experiencing issues within a relationship (e.g., Stirling \& Kerr, 2009). Without clearly

523 differentiating between management and resolution, several effective and ineffective conflict 
524 strategies have been mentioned in the literature. Importantly, the effectiveness of employed

525 strategies may highly depend on situational circumstances and conflict partners’

526 characteristics, thus, whereas some approaches can be clearly positive or negative, some may

527 not be categorized that easily (Mellalieu et al., 2013). Investigating conflict during major

528 competitions, Mellalieu et al. (2013) assessed conflict solving strategies which were

529 employed by sport participants ( $N=90$; e.g., athletes, coaches, staff members). While no

530 participants stated the use of forcing or overpowering behaviours, most participants tried to

531 resolve the conflict either on their own or by looking for help (47\%), while others noted

532 attempts to withdraw from conflict (29\%). This empirical data finds support in several

533 qualitative studies in which athletes were reported to avoid or withdraw from conflicts with

534 team members or coaches and to seek social support in people outside of their sport (e.g.,

535 Gearity \& Murray, 2011; Tamminen et al., 2013). When confronted with low quality

536 coaching or even abusive behaviours athletes reported furthermore to ignore or accept

537 conflicts with coaches (e.g., Gearity \& Murray, 2011; Stirling, 2013; Stirling \& Kerr, 2008).

538 Important requirements for all these conflict management/ resolution strategies are the

539 ability to recognize and address conflict in early stages in order to prevent an escalation due

540 to a summation of emotions and negative behaviours (Holt et al., 2012) and to communicate

541 effectively (e.g., Jowett \& Cockerill, 2002; LaVoi, 2007; Zimmermann, 2009). This includes

542 creating open channels of communication, listening skilfully, just as being able to deliver

543 messages successfully. Most effective conflict strategies are targeting the conflict issue (e.g.,

544 practice schedule, lack of communication, etc.) in a collaborative fashion requiring the

545 willingness of both conflict partners to collaborate. It has been proposed that conflict

546 discussions should preferably take place in structured meetings and with the help of a neutral

547 mediator (Holt et al., 2012; Rovio, Eskola, Kozub, Duda, \& Lintunen, 2009). Here, it is

548 noteworthy that athletes seem to prefer senior players, the captain or sport psychologist to 
549 mediate meetings which concern relational conflicts, whereas the head coach would only be

550 consulted in case of performance conflicts (Holt, Black, Tamminen, Fox, \& Mandigo, 2008;

551 Holt et al., 2012). Different methods and tools have been suggested within the sports

552 literature, these include team building interventions in order to improve communication and

553 build a perception of togetherness, modified performance profiling with an emphasis on

554 relationship quality, as well as team and social skills, win/win strategies in which conflict

555 partners are asked to find a common ground and formulate solutions which enable both to

556 achieve their individual goals, or structured approaches aimed at developing a range of

557 alternative solutions to a problem or broadening individuals’ perspectives by sharing

558 information (Hardy \& Crace, 1997; Holt et al., 2012; Jowett \& Cockerill, 2002; Zimmerman,

559 2009). Besides addressing conflict directly, also seeking social support and gaining

560 perspective about the issue in question have been mentioned within the sport literature

561 (Mellalieu et al., 2013; Rhind \& Jowett, 2010; Tamminen et al., 2013).

562 Finally, approaches targeting emotional intelligence or mindfulness of individuals

563 have been put forward recently. These generally aim to improve individuals’ self-/other-

564 awareness, tolerance, understanding, and psychological flexibility (Chan \& Mallett, 2011;

565 Hayes, 2004; Moore, 2009) and may therefore facilitate conflict management. Perceiving and

566 understanding one's own and the partner's emotions correctly may further enhance

567 interpersonal interaction as it enables conflict partners to consciously regulate emotional

568 responses to disagreements. Individuals may, for example, purposefully show soft emotions

569 in order to down-regulate their conflict partner to prevent negative emotional contagion and

570 conflict escalation (e.g., Overall, Simpson, \& Struthers, 2013; Sandford, 2012).

571 Nevertheless, athletes and coaches have also been found to engage in negative conflict

572 management and resolution strategies. Accordingly, athletes seem to employ more win-loss

573 approaches and aggressive behaviours compared to non-athletes which were explained by the 
574 competitive nature of sport. Besides showing aggressive behavioural tendencies, relational

575 approaches have also been found to be ineffective or even increase interpersonal conflict

576 (Holt et al., 2012; Kerwin et al., 2011). Relational strategies are usually targeting an

577 individual directly (e.g., intelligence, skill level, etc.) rather than aiming at the actual

578 problem, hence, causing feelings of personal affront or threat which in turn lead to reactant

579 behaviours of the conflict partner (Holt et al., 2012; Miron \& Brehm, 2006). Moreover,

580 coaches seem to abuse their power position in terms of physical/emotional punishment, when

581 ignoring athletes' needs or when not integrating them in decision-making processes (e.g.,

582 Bartholomew, Ntoumanis, \& Thøgersen-Ntoumani, 2009; D'Arripe-Longuevill et al., 1998).

\section{Consequences of Interpersonal Conflict}

584 Finally, conflict can lead to consequences which may relate to intrapersonal (e.g.

585 well-being), interpersonal (e.g. termination, cohesion) as well as performance (e.g.

586 competition result) factors and can either be positive, negative or neutral (see Figure 1).

587 Intrapersonal consequences. Interpersonal conflict is likely to influence the manner

588 to which coaches and athletes think, feel and behave. Mellalieu et al. (2013), investigating

589 conflict at major sport events, found that most responses to conflict were perceived negative

$590(65-70 \% ; N=90)$, whereas only few were perceived positive or neutral (5-29\%). Negative

591 cognitive effects included worry, confusion, or even panic; positive cognitions related to

592 increased focus and task clarity. Affective responses covered, for example, frustration,

593 feeling upset, disappointment, but also feeling more positive and confident; behavioural

594 consequences were associated with withdrawal and defensive behaviours, as well as

595 increased motivation and problem solving.

596 Additionally, multiple studies suggest a negative connection between interpersonal

597 conflict and satisfaction (e.g., Paradis et al., 2014b; Sullivan \& Gee, 2007). Further, conflict

598 between coaches and youth athletes may lead to decreased self-description concerning 
599 physiological abilities and overall performance (Jowett \& Cramer, 2010). Athletes may also

600 start to question their identity, skills, lose self-confidence or face emotional break downs after

601 severe disputes. Further, it has been mentioned that conflict between peers can lead to

602 athletes' isolation (Paradis et al., 2014a; Tamminen et al, 2013), increased competitive

603 anxiety and other negative affective responses (Partridge \& Knapp, 2015). Gould et al. (2002)

604 further stated that Olympic coaches perceived conflicts about team selection processes before

605 major competitions and an athlete's involvement in conflict during major competition as

606 inhibiting their own coaching effectiveness. Taken together, poor-quality relationships and

607 interpersonal conflict can increase stress levels in athletes and coaches (e.g. Fletcher et al.,

608 2012; Hanton et al., 2005; Olusoga, Butt, Hays, \& Maynard, 2009) and even lead to quitting

609 the sport (Olusoga, Butt, Maynard, \& Hays, 2010; Stirling, 2013). Conflict may as well have

610 severe health-related consequences. In interaction with other factors, such as a high

611 workload, conflict has shown to increase symptoms of athlete burnout and promote

612 maladaptive eating habits (e.g., Shanmugam, Jowett, \& Meyer, 2013, 2014; Smith,

613 Gustafsson, \& Hassmén, 2010; Tabei, Fletcher, \& Goodger, 2012). However, it is important

614 to keep in mind that multiple variables account for the development of psychological

615 disorders, such as self-esteem, depressive symptoms, perfectionism and attachment

616 (Shanmugam et al., 2013, 2014; Stirling \& Kerr, 2008).

617 In contrast, interpersonal conflict may also facilitate personal growth and skill

618 development, therefore lead to positive outcomes (Tamminen et al., 2013). Thus, athletes

619 reported becoming more aware of their strengths, gaining perspective about their sport and

620 viewing adversity as an ongoing journey. Additionally, athletes seemed to improve their

621 social interactions, were more often willing to help and showed more appreciation for

622 significant others. Overall, it is particularly important to consider positive aspects of conflict

623 in order to challenge the negative connotation of the concept just as to develop a more 
624 effective approach to conflict management. For future studies we suggest to take research on

625 resilience into consideration as the important role of social support and high quality

626 relationships in buffering effects on negative stress responses and increasing individuals'

627 resilience to adversity has been documented recently (Sarkar \& Fletcher, 2014).

628 Interpersonal consequences. Conflict may also have interpersonal or relational

629 consequences, such as relationship deterioration (e.g., disliking), relationship termination,

630 formation of cliques, low team cohesion, deselection, favouritism, quitting a specific

631 team/club and even dropping out of the sport (e.g., Antonini-Phillippe \& Seiler, 2006;

632 Kristiansen et al. 2012; Paradis et al., 2014a; Sullivan \& Feltz, 2001; Tamminen et al., 2013).

633 On the other hand, effective conflict solving strategies may positively influence relationships

634 and cohesion as common goals can be worked out and information about one another is

635 shared, leading to a better understanding of each other (e.g., Sullivan \& Feltz, 2001).

636 Performance consequences. Finally, performance also seems to be affected by

637 conflict; Mellalieu et al. (2013) found a moderate negative influence of interpersonal conflict

638 on individual and team performance during major competitions. As pointed out previously,

639 data was collected from a variety of sport participants, including coaches, managers and other

640 staff members besides athletes. It therefore is possible that the negative effect of conflict on

641 performance was alleviated by non-athlete participants and would have been greater when

642 analysing athletes' data only. This assumption is supported by reports of adolescent athletes

643 who reported a decrease in performance after intra-team conflict (Patridge \& Knapp, 2015) as

644 well as by high-profile athletes who were asked to identify factors influencing their

645 performance at major competitions. Interviewees who previously failed in those major events

646 mentioned the perceived negative impact of issues with coaches, team members and the

647 support network more often than successful athletes (e.g., Gould et al., 2002; Greenleaf et al.,

648 2001). Nevertheless, also positive outcomes of conflict can be found in the literature; for 
649 example, setting up improved training schedules, being more motivated and engaged in 650 practice, or feeling more focused on the task ahead may foster an athlete's performance (Holt 651 et al., 2012; Mellalieu et al., 2013). However, overall the negative consequences of ongoing dysfunctional interpersonal

653 conflict seem to be more severe than positive ones may be helpful, e.g., when comparing 654 increased performance (Paradis et al., 2014a) with heightened stress and health problems 655 (Shanmugam et al., 2013, Tamminen et al., 2013). Hence, preventing conflict and maintaining a high-quality, effective relationship between athletes and their coaches, teammates or support network should be emphasized and facilitated. A recent field study

658 conducted by Musculus, Nau, Lobinger, and Raab (2015) concerning the assessment of 659 psychological variables for diagnostic processes in youth soccer pointed out that cooperation 660 and conflict behaviours are indeed important variables in applied sport psychology as they are taken into account by youth coaches regarding talent selection processes. It will be interesting to see which findings originate from this line of research in future.

\section{Conclusion \& Future Directions}

The apparent lack of a clear conceptual delineation of conflict within the context of sport relationships has prevented research to develop a sound body of theoretical, empirical and practical knowledge around interpersonal conflict. Recent research attempts address conflict within sport, though the lack of a clear conceptualisation and operationalization makes it difficult to compare the results these studies have generated. In this paper, we 669 proposed a definition and conceptual framework (Figure 1) of conflict within sport 670 relationships in an effort to provide the impetus necessary to conduct systematic research.

671 There is an enormous empirical scope including research that aims to study (a) sources of 672 conflict ( e.g., are sources of conflict similar in team and individual sport, across sport and 673 age levels or female and male athletes?); (b) the conflict process (e.g., how is acute conflict 
674 perceived and described by athletes and coaches, how long does a single conflict episode last

675 and why last some conflict episodes longer than others?); (c) conflict prevention and

676 management (e.g., which behaviours do coaches and athletes show to resolve conflict and

677 how do they differ from each other?); (d) conflict outcomes (e.g., how do coaches and

678 athletes cope with conflict personally and what consequences does conflict have for their

679 relationship and performance?). Additionally, research that focuses on testing interventions

680 that aim to prevent and/or manage conflict is warranted. It is also essential to develop

681 psychometric tools that are valid and reliable measures of different aspects of interpersonal

682 conflict. The generated findings of this future research are likely to be more focussed as well

683 as more consistent and less controversial since researchers have a conceptual and operational

684 map to guide them.

685 In summary, a preliminary framework of interpersonal conflict in sport relationships

686 was proposed in an attempt to generate research that is both systematic and focused. Guided

687 by relevant, albeit limited, research surrounding the concept of interpersonal conflict within

688 sport, the content and nature of conflict was discussed as well as its determinants and

689 consequences. In addition, approaches to prevent and manage interpersonal conflict were

690 discussed and were integrated into the proposed framework. Research in this area has

691 practical applications including developing effective and healthy coaching environments

692 where conflict is contained and managed well. 


\section{References}

695 Amason, A. C. (1996). Distinguishing the effects of functional and dysfunctional conflict on 696 strategic decision making: Resolving a paradox for top management teams. Academy

697 of Management Journal, 39, 123-148. doi:10.2307/256633

698

*Antonini Philippe, R., \& Seiler, R. (2006). Closeness, co-orientation and complementarity in

699 coach-athlete relationships: What male swimmers say about their male coaches.

700 Psychology of Sport \& Exercise, 7(2), 159-171. doi:10.1016/j.psychsport.2005.08.004

701

702

703

704

705

706

707

708

709

710

711

712

713

714 Bennie, A., \& O’Connor, D. (2012). Coach-athlete relationships: A qualitative study of 715

716

Arksey, H., \& O'Malley, L. (2005) Scoping studies: towards a methodological framework. International Journal of Social Research Methodology, 8(1), 19-32. doi:10.1080/1364557032000119616

Barki, H., \& Hartwick, J. (2004). Conceptualizing the construct of interpersonal conflict. The International Journal of Conflict Management, 15(3), 216-244. doi:10.1108/eb022913

*Bartholomew, K. J., Ntoumanis, N., \& Thøgersen-Ntoumani, C. (2009). A review of controlling motivational strategies from a self-determination theory perspective: implications for sports coaches. International Review of Sport and Exercise Psychology, 2(2), 215-233. doi:10.1080/17509840903235330

Becker, A. J. (2009). It's not what they do, it's how they do it: athlete experiences of great coaching. International Journal of Sports Science and Coaching, 4(1), 93-119. doi:10.1260/1747-9541.4.1.93 professional sport teams in Australia. International Journal of Sport and Health Science, 10, 58-64. doi:10.5432/ijshs.201208 
717 *Benson, A., Eys, M., Surya, M., Dawson, K., \& Schneider, M. (2013). Athletes’ perceptions 718 of role acceptance in interdependent sport teams. The Sport Psychologist, 27, 269280.

720 Carron, A. V., \& Brawley, L. R. (2012). Cohesion conceptual and measurement issues. Small 721 Group Research, 43(6), 726-743. doi: 10.1177/1046496412468072

722 Carron, A. V, Widmeyer, W, \& Brawley, L. (1985). The development of an instrument to 723 assess cohesion in sport teams: The group environment questionnaire. Journal of Sport Psychology, 7, 244-266.

725

*Chan, J. T., \& Mallett, C. J. (2011). The value of emotional intelligence for high performance coaching. International Journal of Sports Science and Coaching, 6(3),

728 Chelladurai, P., \& Saleh, S. D. (1980). Dimensions of leader behavior in sports: Development 729 of a leadership scale. Journal of Sport Psychology, 2(1), 34-45.

*Copeland, B. W., \& Wida, K. (1996). Resolving team conflict: Coaching strategies to 731 732 prevent negative behavior. Journal of Physical Education, Recreation \& Dance, 67(4), 52-54. doi:10.1080/07303084.1996.10607376

733 Costa, P. T., \& McCrae, R. R. (1992). Four ways five factors are basic. Personality and 734 Individual Differences, 13(6), 653-665. doi:10.1016/0191-8869(92)90236-I

*Culver, D., \& Trudel, P. (2000). Coach-athlete communication within an elite alpine ski 736 team. Journal of Excellence, 3, 28-54.

737 Cunningham, I. J., \& Eys, M. A. (2007). Role ambiguity and intra-team communication in 738 interdependent sport teams. Journal of Applied Social Psychology, 37(10), 22202237. doi:10.1111/j.1559-1816.2007.00256.x 
*d'Arripe-Longueville, F., Fournier, J. F., \& Dubois, A. (1998). The perceived effectiveness of interactions between expert French judo coaches and elite female athletes. The Sport Psychologist, 12, 317-332.

*Davis, L., \& Jowett, S. (2014a). Coach-athlete attachment and the quality of the coachathlete relationship: Implications for athlete’s well-being. Journal of Sports Sciences, 32(15), 1454-64. doi:10.1080/02640414.2014.898183

Deutsch, M. (1969). Socially relevant science: reflections on some studies of interpersonal conflict. American Psychologist, 24(12), 1076-1092. doi:10.1037/h0028993

Digman, J. M. (1990). Personality structure: Emergence of the five-factor model. Annual Review of Psychology, 41(1), 417-440. doi: 10.1146/annurev.ps.41.020190.002221

Dixon-Woods, M., Agarwal, S., Jones, D., Young, B., \& Sutton, A. (2005). Synthesising qualitative and quantitative evidence: a review of possible methods. Journal of Health Services Research \& Policy, 10(1), 45-53B. doi:10.1177/1468794107078517

*Dupuis, M., Bloom, G., \& Loughead, T. (2006). Team captains’ perceptions of athlete leadership. Journal of Sport Behavior,29(1), 60-78.

*Duquin, M. E., \& Schroeder-Braun, K. (1996). Power, empathy, and moral conflict in sport. Peace and Conflict: Journal of Peace Psychology, 2(4), 351-367. doi:10.1207/s15327949pac0204_6

Evans, A. L., Slater, M. J., Turner, M. J., \& Barker, J. B. (2013). Using personal-disclosure mutual-sharing to enhance group functioning in a professional soccer academy. The Sport Psychologist, 27, 233-243.

Felton, L., \& Jowett, S. (2013a). "What do coaches do" and "how do they relate": Their effects on athletes' psychological needs and functioning. Scandinavian Journal of Medicine \& Science in Sports, 23(2), e130-e139. doi: 10.1111/sms.12029 
764 Felton, L., \& Jowett, S. (2013b). Attachment and well-being: The mediating effects of

765

766

767

768

769

770

771

772

773

774

775

776

777

778

779

780

781

782

783

784

785

786

787 psychological needs satisfaction within the coach-athlete and parent-athlete relational contexts. Psychology of Sport \& Exercise, 14(1), 57-65. doi:10.1016/j.psychsport.2012.07.006

*Felton, L., \& Jowett, S. (2013c). The mediating role of social environmental factors in the associations between attachment styles and basic needs satisfaction. Journal of Sports Sciences, 31(6), 618-28. doi:10.1080/02640414.2012.744078

*Fletcher, D., \& Hanton, S. (2003). Organisational stress in elite sport. The Sport Psychologist, 17, 175-195.

*Fletcher, D., Hanton, S., Mellalieu, S. D., \& Neil, R. (2012). A conceptual framework of organizational stressors in sport performers. Scandinavian Journal of Medicine \& Science in Sports, 22(4), 545-57. doi: 10.1111/j.1600-0838.2010.01242.x

*Fransen, K., Vanbeselaere, N., De Cuyper, B., Vande Broek, G., \& Boen, F. (2014). The myth of the team captain as principal leader: extending the athlete leadership classification within sport teams. Journal of Sports Sciences, 32(14), 1-9. doi:10.1080/02640414.2014.891291

Gearity, B. T. (2012). Poor teaching by the coach: A phenomenological description from athletes’ experience of poor coaching. Physical Education \& Sport Pedagogy, 17(1), 79-96. doi:10.1080/17408989.2010.548061

*Gearity, B. T., \& Murray, M. A. (2011). Athletes’ experiences of the psychological effects of poor coaching. Psychology of Sport and Exercise, 12(3), 213-221. doi:10.1016/j.psychsport.2010.11.004

*Gould, D., Greenleaf, C., Chung, Y., \& Guinan, D. (2002). A survey of US Atlanta and Nagano Olympians: Variables perceived to influence performance. Research 
Quarterly for Exercise and Sport, 73(2), 175-186.

789 doi:10.1080/02701367.2002.10609006

790

*Gould, D., Guinan, D., Greenleaf, C., \& Chung, Y. (2002). A survey of US Olympic

791 coaches: Variables perceived to have influenced athlete performances and coach

792 effectiveness. The Sport Psychologist, 16(3), 229-250.

793

*Greenleaf, C., Gould, D., \& Dieffenbach, K. (2001). Factors influencing Olympic

794 performance: Interviews with Atlanta and Nagano US Olympians. Journal of Applied 795 Sport Psychology, 13(2), 154-184. doi:10.1080/104132001753149874

796

797

798

799

800

801

802

803

804

805

806

807

808

809

810

*Hampson, R. \& Jowett, S. (2014). Effects of coach leadership and coach-athlete relationship on collective efficacy. Scandinavian Journal of Medicine \& Science in Sport, 24(2), 454-460. doi: 10.1111/j.1600-0838.2012.01527.x

*Hanton, S., Fletcher, D., \& Coughlan, G. (2005). Stress in elite sport performers: A comparative study of competitive and organizational stressors. Journal of Sports Sciences, 23(10), 1129-41. doi:10.1080/02640410500131480

*Hardy, C. J., \& Crace, R. K. (1997). Foundations of team building: Introduction to the team building primer. Journal of Applied Sport Psychology, 9(1), 1-10. doi:10.1080/10413209708415381

*Hardy, J., Eys, M. A., \& Carron, A. V. (2005). Exploring the potential disadvantages of high cohesion in sport teams. Small Group Research, 36, 166-187. doi: $10.1177 / 1046496404266715$

Hayes, S. C. (2004). Acceptance and Commitment Therapy, Relational Frame Theory, and the Third Wave of Behavioral and Cognitive Therapies. Behavior Therapy, 35, 639665. doi:10.1016/S0005-7894(04)80013-3 
811 *Holt, N. L., Black, D. E., Tamminen, K. A., Fox, K. R., \& Mandigo, J. L. (2008). Levels of social complexity and dimensions of peer experiences in youth sport. Journal of Sport \& Exercise Psychology, 30, 411-431.

814 *Holt, N., Knight, C., \& Zukiwski, P. (2012). Female athletes’ perceptions of teammate conflict in sport: Implications for sport psychology consultants. The Sport Psychologist, 26, 135-154.

817 Jackson, B., Dimmock, J. A., Gucciardi, D. F., \& Grove, J. R. (2010). Relationship commitment in athletic dyads: Actor and partner effects for Big Five self- and otherratings. Journal of Research in Personality, 44(5), 641-648.

820 doi:10.1016/j.jrp.2010.08.004

821

822

823

824

825

826

827

828

829

830

831

832

833

834

835
*Jackson, B., Dimmock, J. A., Gucciardi, D. F., \& Grove, J. R. (2011). Personality traits and relationship perceptions in coach-athlete dyads: Do opposites really attract? Psychology of Sport and Exercise, 12(3), 222-230. doi:10.1016/j.psychsport.2010.11.005

Jackson, B., Grove, J. R., \& Beauchamp, M. R. (2010). Relational efficacy beliefs and relationship quality within coach-athlete dyads. Journal of Social and Personal Relationships, 27(8), 1035-1050. doi: 10.1177/0265407510378123

*Jackson, B., Gucciardi, D., \& Dimmock, J. A. (2011). Tripartite efficacy profiles: A cluster analytic investigation of athletes’ perceptions of their relationship with their coach. Journal of Sport \& Exercise Psychology, 33, 394-415.

Jackson, B., Knapp, P., \& Beauchamp, M. R. (2008). Origins and consequences of tripartite efficacy beliefs within elite athlete dyads. Journal of Sport \& Exercise Psychology, 30(5), 512.

*Jones, R. L. (2002). The black experience within English semiprofessional soccer. Journal of Sport \& Social Issues, 26(1), 47-65. doi:10.1177/0193723502261004 
836 *Jowett, S. (2003). When the "Honeymoon" is over: a case study of a coach-athlete dyad in 837 crisis. The Sport Psychologist, 17, 444-460.

838 Jowett, S. (2005). The coach-athlete partnership. The Psychologist, 18(7), 412-415.

839 *Jowett, S. (2008). Moderators and mediators of the association between the coach-athlete 840 relationship and physical self-concept. International Journal of Coaching Science, 2, 43-62.

842 *Jowett, S. (2009). Validating coach-athlete relationship measures with the nomological network. Measurement in Physical Education and Exercise Science, 13, 1-18.

844 doi:10.1080/10913670802609136

845 *Jowett, S., \& Carpenter, P. (2004, October) Coaches’and athletes’ perceptions of rules in the coach-athlete relationship. Poster presentation at the Annual Conference of the Association of the Advancement of Applied Sport Psychology. Minnesota, USA

Jowett, S., \& Chaundy, V. (2004). An investigation into the impact of coach leadership and coach-athlete relationship on group cohesion. Group Dynamics: Theory, Research and Practice, 8, 302-311. doi:10.1037/1089-

851 *Jowett, S., \& Cockerill, I. (2003). Olympic medallists’ perspective of the athlete-coach relationship. Psychology of Sport and Exercise, 4(4), 313-331. doi:10.1016/S1469-

853 0292(02)00011-0

854 *Jowett, S., \& Cramer, D. (2010). The prediction of young athletes’ physical self from 855 perceptions of relationships with parents and coaches. Psychology of Sport and $856 \quad$ Exercise, 11(2), 140-147. doi:10.1016/j.psychsport.2009.10.001

857 Jowett, S. \& Felton, L. (2014). Coach-athlete relationships and attachments. In M. 858 Beauchamp \& M. Eys (Eds.), Group Dynamics Advances in Sport and Exercise Psychology (Second Edition). New York: Routledge. 
860 *Jowett, S., \& Frost, T. (2007). Race/Ethnicity in the all-male coach-athlete relationship:

861 Black footballers’ narratives. International Journal of Sport and Exercise Psychology, 5(3), 255-269. doi:10.1080/1612197X.2007.9671835

*Jowett, S., Lafreniere, M. A. K., \& Vallerand, R. J. (2012). Passion for activities and relationship quality: A dyadic approach. Journal of Social and Personal Relationships, 30(6), 734-749. doi:10.1177/0265407512467748

Jowett, S., \& Shanmugam, V. (in press). Relational coaching in sport: Its psychological underpinnings and practical effectiveness. In R. Schinke, K.R. McGannon, B. Smith, Routledge International Handbook of Sport Psychology. Routledge.

869 *Jowett, S., \& Timson-Katchis, M. (2005). Social networks in sport: Parental influence on 870 the coach-athlete relationship. The Sport Psychologist, 19, 267-287.

871 *Kerwin, S., Doherty, A., \& Harman, A. (2011). “It’s Not Conflict, It's Differences of 872 Opinion”: An in-depth examination of conflict in nonprofit boards. Small Group Research, 42(5), 562-594. doi:10.1177/1046496411398395

874 *Khomutova, A. (2015, ahead of print). Basketball coaches' experience in working with 875 multicultural teams: Central and Northern European perspectives. Sport in Society. doi:10.1080/17430437.2015.1067777

*Kristiansen, E., Tomten, S. E., Hanstad, D. V, \& Roberts, G. C. (2012). Coaching communication issues with elite female athletes: two Norwegian case studies. Scandinavian Journal of Medicine \& Science in Sports, 22(6), 156-67. doi:10.1111/j.1600-0838.2012.01521.x

881 Langan, E., Blake, C., \& Lonsdale, C. (2013). Systematic review of the effectiveness of 882 interpersonal coach education interventions on athlete outcomes. Psychology of Sport and Exercise, 14(1), 37-49. doi:10.1016/j.psychsport.2012.06.007 
884

885

886

887

888

889

890

891

892

893

894

895

896

897

898

899

900

901

902

903

904

905

906

907

*Lauer, L., Gould, D., Roman, N., \& Pierce, M. (2010). Parental behaviors that affect junior tennis player development. Psychology of Sport and Exercise, 11(6), 487-496. doi:10.1016/j.psychsport.2010.06.008

*LaVoi, N. M. (2007). Interpersonal communication and conflict in the coach-athlete relationship. In S. Jowett \& D. E. Lavallee (Eds.), Social Psychology in Sport (1st ed., pp. 29-40). Champaign: Human Kinetics.

LaVoi, N. M., \& Dutove, J. K. (2012). Barriers and supports for female coaches: An ecological model. Sports Coaching Review, 1(1), 17-37. doi:10.1080/21640629.2012.695891

*Leo, F. M., González-Ponce, I., Sánchez-Miguel, P. A., Ivarsson, A., \& García-Calvo, T. (2015). Role ambiguity, role conflict, team conflict, cohesion and collective efficacy in sport teams: A multilevel analysis. Psychology of Sport and Exercise, 20, 60-66. doi:10.1016/j.psychsport.2015.04.009

Mageau, G. A., \& Vallerand, R. J. (2003). The coach-athlete relationship: A motivational model. Journal of Sports Sciences, 21(11), 883-904. doi:10.1080/0264041031000140374

*Magnusen, M. (2010). Differences in strength and conditioning coach self-perception of leadership style behaviors at the National Basketball Association, Division I, and Division II levels. The Journal of Strength \& Conditioning Research, 24(6), 14401450. doi: 10.1519/JSC.0b013e3181d321ec

*Mazerolle, S. M., Bruening, J. E., \& Casa, D. J. (2008). Work-family conflict, part I: Antecedents of work-family conflict in national collegiate athletic association division I-A certified athletic trainers. Journal of Athletic Training, 43(5), 505-12. doi:10.4085/1062-6050-43.5.505 
908

909

910

911

912

913

914

915

916

917

918

919

920

921

922

923

924

925

926

927

928

929

930

931

*Mellalieu, S., Shearer, D. A., \& Shearer, C. (2013). A preliminary survey of interpersonal conflict at major games and championships. The Sport Psychologist, 27, 120-129.

Miron, A. M., \& Brehm, J. W. (2006). Reactance theory-40 years later. Zeitschrift für Sozialpsychologie, 37(1), 9-18. doi:10.1024/0044-3514.37.1.9

Moore, Z. E. (2009). Theoretical and empirical developments of the (MAC) approach to performance enhancement. Journal of Clinical Sports Psychology, 4, 291-302.

*Morgan, P. B., Fletcher, D., \& Sarkar, M. (2013). Defining and characterizing team resilience in elite sport. Psychology of Sport and Exercise, 14(4), 549-559. doi:10.1016/j.psychsport.2013.01.004

*Musculus, L., Nau, A., Lobinger, B., \& Raab, M. (2015). Die Erfassung psychologischer Variablen im Nachwuchsleistungsfußball - Implikationen Psychologischer Diagnostik für die Praxis der Talentselektion. In K. Wunsch, J. Mueller, H. Mothes, A. Schoendube, N. Hartmann, \& R. Fuchs (Eds.) Stressregulation und Sport. 47. Jahrestagung der Arbeitsgemeinschaft für Sportpsychologie (asp), 47.

*Olusoga, P., Butt, J., Hays, K., \& Maynard, I. (2009). Stress in elite sports coaching: Identifying stressors. Journal of Applied Sport Psychology, 21(4), 442-459. doi:10.1080/10413200903222921

Olusoga, P., Butt, J., Maynard, I., \& Hays, K. (2010). Stress and coping: A study of world class coaches. Journal of Applied Sport Psychology, 22(3), 274-293. doi:10.1080/10413201003760968

*Ommundsen, Y., Roberts, G. C., Lemyre, P. N., \& Miller, B. W. (2005). Peer relationships in adolescent competitive soccer: Associations to perceived motivational climate, achievement goals and perfectionism. Journal of Sports Sciences, 23(9), 977-989. doi:10.1080/02640410500127975 
932 Overall, N. C., Simpson, J. A., \& Struthers, H. (2013). Buffering attachment-related avoidance: Softening emotional and behavioral defenses during conflict discussions. Journal of Personality and Social Psychology, 104(5), 854. Doi:10.1037/a0031798

Paletz, S. B., Miron-Spektor, E., \& Lin, C. C. (2014). A cultural lens on interpersonal conflict and creativity in multicultural environments. Psychology of Aesthetics, Creativity, and the Arts, 8(2), 237-252.

*Paradis, K. F., Carron, A. V, \& Martin, L. J. (2014a). Athlete perceptions of intra-group 939 conflict in sport teams. Sport \& Exercise Psychology Review, 10(3), 4-18.

*Paradis, K., Carron, A., \& Martin, L. (2014b). Development and validation of an inventory to assess conflict in sport teams: the Group Conflict Questionnaire. Journal of Sports Sciences, 32(20), 1966-1978. doi:10.1080/02640414.2014.970220

*Partridge, J. A., \& Knapp, B. A. (2016). Mean girls: Adolescent female athletes and peer conflict in sport. Journal of Applied Sport Psychology, 28(1), 113-127. doi:10.1080/10413200.2015.1076088

*Potrac, P., \& Jones, R. (2009). Power, conflict, and cooperation: Toward a micropolitics of coaching. Quest, 61(2), 223-236. doi:10.1080/00336297.2009.10483612

*Purdy, L., Potrac, P., \& Jones, R. (2008). Power, consent and resistance: An autoethnography of competitive rowing. Sport, Education and Society, 13(3), 319-336. doi:10.1080/13573320802200693

951 Rahim, M. A. (2002). Toward a theory of managing organizational conflict. International Journal of Conflict Management, 13(3), 206-235. doi:10.2139/ssm.437684

$953 *$ Rhind, D. J., \& Jowett, S. (2010). Relationship maintenance strategies in the coach-athlete 954 relationship: The development of the COMPASS Model. Journal of Applied Sport Psychology, 22(1), 106-121. doi:10.1080/10413200903474472 
956

957

958

959

960

961

962

963

964

965

966

967

968

969

970

971

972

973

974

975

976

977

978

*Rhind, D., \& Jowett, S. (2011). Working with coach-athlete relationships: Their quality and maintenance. In S. Mellalieu \& S. Hanton (Eds.), Professional Practice in Sport Psychology: A Review (219-248). Routledge

*Rhind, D. J., \& Jowett, S. (2012). Development of the Coach-Athlete Relationship Maintenance Questionnaire (CARM-Q). International Journal of Sports Science and Coaching, 7(1), 121-138. doi:10.1260/1747-9541.7.1.121

Rovio, E., Eskola, J., Kozub, S. A., Duda, J. L., \& Lintunen, T. (2009). Can high group cohesion be harmful?: A case study of a junior ice-hockey team. Small Group Research, 40(4), 421-435. doi:10.1177/1046496409334359

Ryan, R. M., \& Deci, E. L. (2000). Self-determination theory and the facilitation of intrinsic motivation, social development, and well-being. The American Psychologist, 55(1), 68-78. doi:10.1037/0003-066X.55.1.68

*Sagar, S. S., \& Jowett, S. (2012). Communicative acts in coach-athlete interactions: When losing competitions and when making mistakes in training. Western Journal of Communication, 76(2), 148-174. doi:10.1080/10570314.2011.651256

Sanford, K. (2007). Hard and soft emotion during conflict: Investigating married couples and other relationships. Personal Relationships, 14(1), 65-90. doi: 10.1111/j.14756811.2006.00142.x

Sanford, K. (2012). The communication of emotion during conflict in married couples. Journal of Family Psychology, 26(3), 297. doi:10.1037/a0028139

Sarkar, M., \& Fletcher, D. (2014). Psychological resilience in sport performers: A review of stressors and protective factors. Journal of Sports Sciences, 32(15), 1419-1434. doi:10.1080/02640414.2014.901551 
979 *Scanlan, T. K., Stein, G. L., \& Ravizza, K. (1991). An in-depth study of former elite figure 980 skaters: III. Sources of stress. Journal of Sport \& Exercise Psychology, 13(2), 103-

*Shanmugam, V., Jowett, S., \& Meyer, C. (2013). Eating psychopathology amongst athletes: The importance of relationships with parents, coaches and teammates. International Journal of Sport \& Exercise Psychology, 11(1), 24-38.

985 doi:10.1080/1612197X.2012.724197

*Shanmugam, V., Jowett, S., \& Meyer, C. (2014). Interpersonal difficulties as a risk factor for athletes’ eating psychopathology. Scandinavian Journal of Medicine \& Science in Sports, 24(2), 469-76. doi:10.1111/sms.12109

*Shaw, S., \& Allen, J. B. (2009). The experiences of high performance women coaches: A 990 case study of two Regional Sport Organisations. Sport Management Review, 12(4), 217-228. doi:10.1016/j.smr.2009.03.005

992

Short, S. E., Sullivan, P., \& Feltz, D. L. (2005). Development and preliminary validation of 993 the collective efficacy questionnaire for sports. Measurement in Physical Education and Exercise Science, 9(3), 181-202. doi:10.1207/s15327841mpee0903_3

*Shrier, I., Safai, P., \& Charland, L. (2014). Return to play following injury: whose decision should it be? British Journal of Sports Medicine, 48(5), 394-401. doi:10.1136/bjsports-2013-092492

*Smith, S. R. (2001). The toughest game - reducing conflict with parents and players. perceived motivational climate, perceived peer relationships, and motivation-related responses of youth athletes. Journal of Sports Sciences, 24(12), 1315-27. 
1004

1005

1006

1007

1008

1009

1010

1011

1012

1013

1014

1015

1016

1017

1018

1019

1020

1021

1022

1023

1024

1025

1026

1027

*Smith, A. L., Gustafsson, H., \& Hassmén, P. (2010). Peer motivational climate and burnout perceptions of adolescent athletes. Psychology of Sport and Exercise, 11(6), 453-460. doi:10.1016/j.psychsport.2010.05.007

*Smith, M. J., Arthur, C. A., Hardy, J., Callow, N., \& Williams, D. (2013). Transformational leadership and task cohesion in sport: The mediating role of intrateam communication. Psychology of Sport and Exercise, 14(2), 249-257. doi:10.1016/j.psychsport.2012.10.002

Smith, R., \& Smoll, F. (1997). Coach-mediated team building in youth sports. Journal of Applied Sport Psychology, 9, 37-41. doi:10.1080/10413209708415387

Smoll, F. L., \& Smith, R. E. (1989). Leadership behaviors in sport: A theoretical model and research paradigm. Journal of Applied Social Psychology, 19(18), 1522-1551. doi: 10.1111/j.1559-1816.1989.tb01462.x

Stirling, A. E. (2013). Understanding the use of emotionally abusive coaching practices. International Journal of Sports Science and Coaching, 8(4), 625-640. doi:10.1260/1747-9541.8.4.625

*Stirling, A., \& Kerr, G. A. (2008). Elite female swimmers’ experiences of emotional abuse across time. Journal of Emotional Abuse, 7(4), 89-113. doi:10.1300/J135v07n04

*Stirling, A. E., \& Kerr, G. A. (2009). Abused athletes’ perceptions of the coach-athlete relationship. Sport in Society, 12(2), 227-239. doi:10.1080/17430430802591019

*Sullivan, P. (2004). Communication differences between male and female team sport athletes. Communication Reports, 17(2), 121-128. doi:10.1080/08934210409389381

*Sullivan, P. J., \& Feltz, D. L. (2001). The relationship between intrateam conflict and cohesion within hockey teams. Small Group Research, 32(3), 342-355. doi:10.1177/104649640103200304 
1028

1029

1030

1031

1032

1033

1034

1035

1036

1037

1038

1039

1040

1041

1042

1043

1044

1045

1046

1047

1048

1049

1050

*Sullivan, P. J., \& Feltz, D. L. (2003). The preliminary development of the Scale for Effective Communication in Team Sports (SECTS). Journal of Applied Social Psychology, 33(8), 1693-1715. doi: 10.1111/j.1559-1816.2003.tb01970.x

*Sullivan, P. J., \& Gee, C. J. (2007). The relationship between athletic satisfaction and intrateam communication. Group Dynamics: Theory, Research, and Practice, 11(2), 107-116. doi:10.1037/1089-2699.11.2.107

*Tabei, Y., Fletcher, D., \& Goodger, K. (2012). The relationship between organizational stressors and athlete burnout in soccer players. Journal of Clinical Sport Psychology, $6,146-165$.

*Tamminen, K. A., Holt, N. L., \& Neely, K. C. (2013). Exploring adversity and the potential for growth among elite female athletes. Psychology of Sport and Exercise, 14(1), 2836. doi:10.1016/j.psychsport.2012.07.002

*Tomlinson, A., \& Yorganci, I. (1997). Male coach/female athlete relations: Gender and power relations in competitive sport. Journal of Sport \& Social Issues, 21(2), 134155. doi:10.1177/019372397021002003

*Trzaskoma-Bicsérdy, G., Bognár, J., Révész, L., \& Géczi, G. (2007). The coach-athlete relationship in successful Hungarian individual sports. International Journal of Sports Science and Coaching, 2(4), 485-495. doi:10.1260/174795407783359759

Vallerand, R. J. \& Miquelon, P. (2007). Passion for sport in athletes. In S. Jowett and D. Lavallee (Eds.) Social Psychology in Sport. Champaign: Human Kinetics.

Volkema, R., \& Bergmann, T. (1995). Conflict styles as indicators of behavioral patterns in interpersonal conflicts. The Journal of Social Psychology, 135(1), 5-15. doi:10.1080/00224545.1995.9711395 
1051 *Weiss, M. R., \& Fretwell, S. D. (2005). The parent-coach/child-athlete relationship in youth sport: cordial, contentious, or conundrum? Research Quarterly for Exercise \& Sport, 76(3), 286-305. doi:10.1080/02701367.2005.10599300

1055

*Weiss, M., \& Smith, A. (2002). Friendship quality in youth sport: Relationship to age, gender, and motivation variables. Journal of Sport \& Exercise Psychology, 24, 420-

1056 437.

1057

Wylleman, P. (2000). Interpersonal relationships in sport: Uncharted territory in sport psychology research. International Journal of Sport Psychology, 31, 555-572.

*Zimmerman, E. P. (2009). Conflict resolution strategies and improving relationships for ATs. Athletic Therapy Today, 14(4), 36-39.

Yang, S. X., \& Jowett, S. (2013). Conceptual and measurement issues of the complementarity dimension of the coach-athlete relationship across cultures. Psychology of Sport and Exercise, 14(6), 830-841. doi:10.1016/j.psychsport.2013.06.003

1064 Yang, S. X., Jowett, S., \& Chan, D.K. (2015). Effects of the Big-Five personality traits on the 1065 quality of relationship and satisfaction in coach-athlete dyads. Scandinavian Journal of Medicine \& Science in Sports, 25(4), 568-580. doi: 10.1111/sms.12329 
1068

1069 Figure 1. A comprehensive framework of interpersonal conflict in sport relationships.

1070

1071

1072

1073

1074

1075

1076

1077

1078

1079

1080

1081

1082

1083

1084

1085

1086

1087

1088

1089

1090

1091

1092

1093

1094

1095

1096

1097

1098 